\title{
Fracture liaison programs
}

Citation for published version (APA):

Geusens, P., Bours, S. P. C., Wyers, C. E., \& van den Bergh, J. P. (2019). Fracture liaison programs. Best Practice \& Research in Clinical Rheumatology, 33(2), 278-289.

https://doi.org/10.1016/j.berh.2019.03.016

Document status and date:

Published: 01/04/2019

DOI:

10.1016/j.berh.2019.03.016

Document Version:

Publisher's PDF, also known as Version of record

Document license:

Taverne

Please check the document version of this publication:

- A submitted manuscript is the version of the article upon submission and before peer-review. There can be important differences between the submitted version and the official published version of record.

People interested in the research are advised to contact the author for the final version of the publication, or visit the DOI to the publisher's website.

- The final author version and the galley proof are versions of the publication after peer review.

- The final published version features the final layout of the paper including the volume, issue and page numbers.

Link to publication

\footnotetext{
General rights rights.

- You may freely distribute the URL identifying the publication in the public portal. please follow below link for the End User Agreement:

www.umlib.nl/taverne-license

Take down policy

If you believe that this document breaches copyright please contact us at:

repository@maastrichtuniversity.nl

providing details and we will investigate your claim.
}

Copyright and moral rights for the publications made accessible in the public portal are retained by the authors and/or other copyright owners and it is a condition of accessing publications that users recognise and abide by the legal requirements associated with these

- Users may download and print one copy of any publication from the public portal for the purpose of private study or research.

- You may not further distribute the material or use it for any profit-making activity or commercial gain

If the publication is distributed under the terms of Article $25 \mathrm{fa}$ of the Dutch Copyright Act, indicated by the "Taverne" license above, 


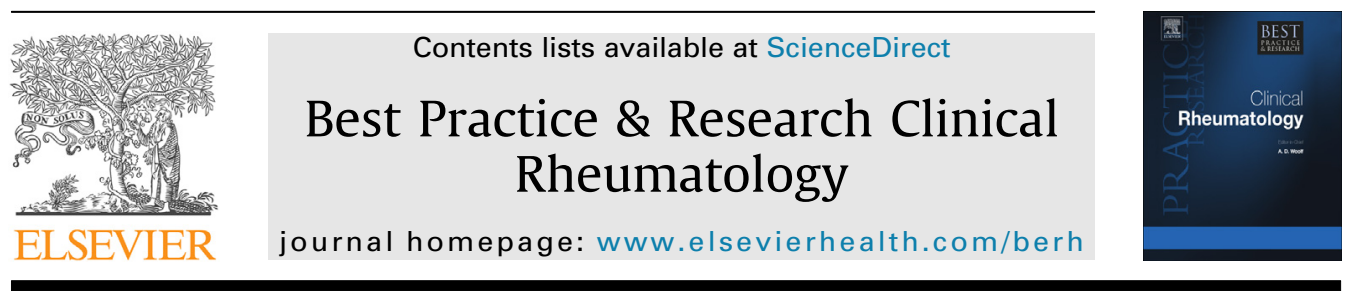

5

\title{
Fracture liaison programs
}

\author{
Piet Geusens ${ }^{\text {a, b, * }}$, Sandrine P.G. Bours ${ }^{\text {a }}$, Caroline E. Wyers ${ }^{c, d}$, \\ Joop P. van den Bergh ${ }^{b, c, d}$
}

a Department of Internal Medicine, Subdivision Rheumatology, CAPHRI Care and Public Health Research Institute, Maastricht University Medical Centre +, P.O. Box 5800, 6202 AZ Maastricht, the Netherlands

${ }^{\mathrm{b}}$ Biomedical Research Centre, Hasselt University, Agoralaan, Gebouw D, 3590 Diepenbeek, Belgium

${ }^{\mathrm{c}}$ Department of Internal Medicine, NUTRIM School of Nutrition and Translational Research in Metabolism, Maastricht University Medical Centre +, P.O. Box 5800, 6202 AZ Maastricht, the Netherlands

d Department of Internal Medicine, VieCuri Medical Centre, Tegelseweg 210, 5912 BL Venlo, the Netherlands

Keywords:

Fracture liaison service

Orthogeriatric care

Implementation

Fracture risk evaluation

Secondary osteoporosis

Secondary fracture prevention

Cost/effectiveness

\begin{abstract}
A B S T R A C T
In view of the high imminent risk of having subsequent fractures after a fracture, early evaluation and treatment decisions to prevent subsequent fractures are advocated. After a hip fracture, the fracture liaison service (FLS) and orthogeriatric care are considered the most appropriate organisational approaches for secondary fracture prevention following a recent fracture.

Their introduction and implementation have been shown to increase evaluation and treatment of patients at high risk for subsequent fracture. Of real-world cohort studies, most, but not all studies, indicate a lower incidence of fracture and longer survival after treatment with nitrogen-containing bisphosphonates.
\end{abstract}

(c) 2019 Elsevier Ltd. All rights reserved.

At the age of 50 years, $50 \%$ of women and $25 \%$ of men will sustain a fracture during the remaining lifetime [1]. Subsequent fractures contribute substantially to this overall fracture burden. Of all lowtrauma fractures after the age of 40 years, $40 \%$ of fractures in women and $24 \%$ in men are subsequent fractures [2]. Nearly all fractures are associated with an increased risk for future fracture, regardless of age, baseline bone mineral density (BMD) and fracture location [3-5]. Furthermore, most

\footnotetext{
* Corresponding author. Department of Internal Medicine, Subdivision Rheumatology, CAPHRI Care and Public Health Research Institute, Maastricht University Medical Centre +, P.O. Box 5800, 6202 AZ Maastricht, the Netherlands.

E-mail addresses: piet.geusens@scarlet.be (P. Geusens), s.bours@mumc.nl (S.P.G. Bours), cwyers@viecuri.nl (C.E. Wyers), jvdbergh@viecuri.nl (J.P. van den Bergh).
} 
subsequent fractures occur within the first years after a fracture, which is refereed as the imminent fracture risk', i.e. the risk of having subsequent fracture is higher in short term than in long term after a fracture [6].

To prevent subsequent fractures, patients with a recent fracture are, therefore, in need of adequate evaluation and treatment decisions shortly after the initial fracture. However, there is still a large gap in the number of patients with a recent fracture who are actually evaluated and treated [7-9]. In this context, the American Society of Bone and Mineral Research (ASBMR), the International Osteoporosis Foundation (IOF) and the European League against Rheumatism (EULAR) together with the European Federation of National Associations of Orthopaedics and Traumatology (EFORT) have formulated recommendations for secondary fracture prevention [10-12].

The FLS is considered the most effective organisational structure to increase evaluation and treatment after any fracture [13] and orthogeriatric care in frail elderly after hip fracture (meta-analysis and randomised control trial (RCT))[13].

\section{The four pillars of an FLS}

Building up an FLS requires four pillars (Fig. 1). The first pillar consists of a bone leader, a coordinator, a multidisciplinary team and a business plan to run an FLS [10-12,14,15]. The bone leader is a specialist in metabolic bone diseases who takes care of the organisation of a multidisciplinary team in consultation with the orthopaedic surgeons. The coordinator, often a well-educated nurse, is responsible for organising the diagnostic investigations and to help starting interventions and providing adequate medical information to patients and general practitioners (GPs) [10-12,16,17].

The second pillar consists of the identification of all patients with a recent fracture and the selection of patients for invitation to the FLS [10-12]. Selected patients have to be educated, contacted and invited $[13,18]$. This can be performed at the emergency department, at the plaster consultation, in the hospital when patients are hospitalised, at the orthogeriatric care unit and at post-treatment stage after fracture healing, by regular fracture database consultation, information letter, telephone call and

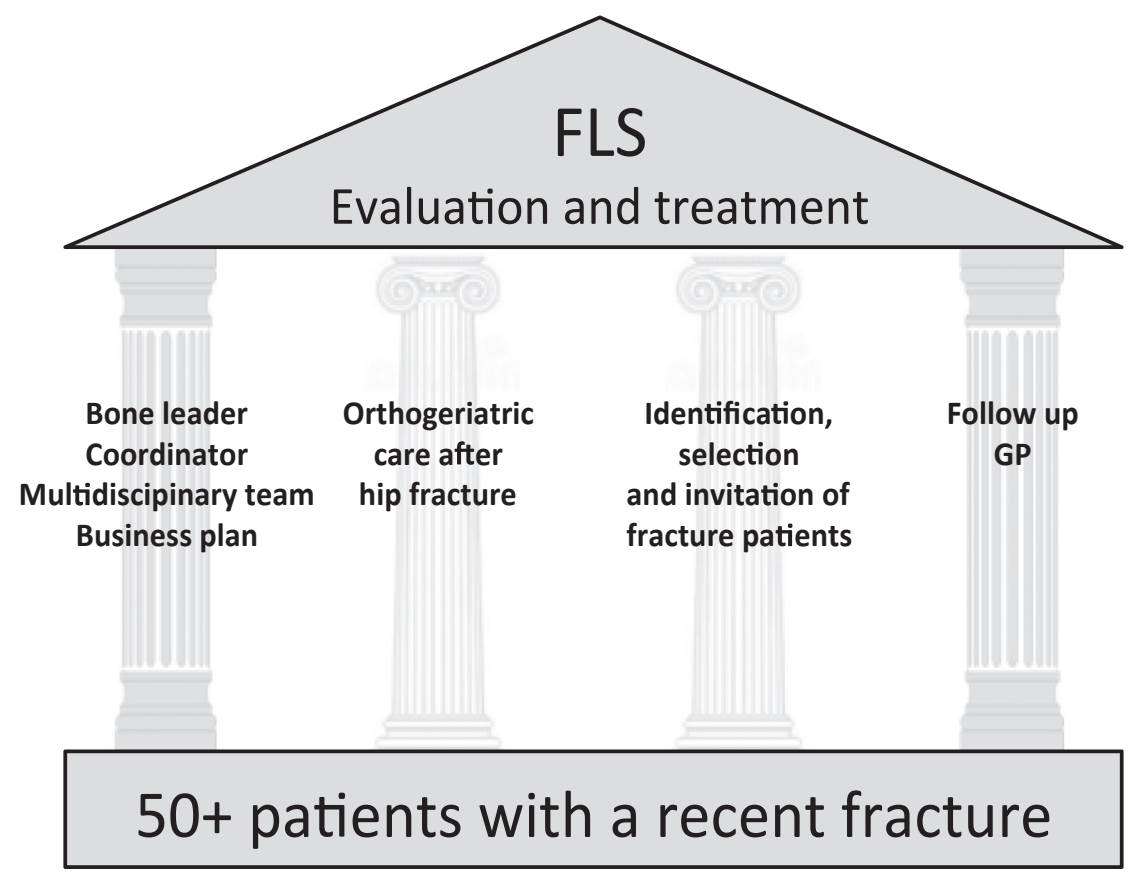

Fig. 1. The four pillars of an FLS. 
e-mail. Such coordinator-supported approach has been shown to significantly increase evaluation and treatment initiation $[13,19]$.

A third pillar consists of orthogeriatric care, which focuses on patients with a recent hip fracture. Orthogeriatric services are designed to provide specialist geriatric care to the frail older trauma patient and are integral to multidisciplinary management following admission preoperatively, peri-operatively and post-operatively. The components include rapid optimisation of fitness for surgery, early identification of rehabilitation goals to facilitate return to pre-fracture residence and long-term well-being, as appropriate, and integrating with related services within secondary care and the community, including secondary fracture prevention. The development of orthogeriatrician-led FLS models focuses mainly on patients with hip fractures but could also be a model for admitted frail elderly with a recent major fracture, whereas ambulatory patients with non-vertebral fractures (NVFs) and vertebral fractures (VFs) are preferably managed in an outpatient FLS setting [20-22].

The fourth pillar is communication with the GP and organisation of adequate follow up.

\section{Reasons for evaluation and treatment gap after a fracture}

Currently, there is a substantial treatment gap for osteoporosis in general, which is highly variable throughout Europe, i.e. between 25\% and 95\% [8,23,24]. Various reasons have been documented for this gap.

Most patients perceive their risk for future fractures as low [25], also patients with comorbidities such as neurologic, rheumatologic, respiratory and gastro-intestinal comorbidities [26]. Even patients with postmenopausal osteoporosis perceive fractures as random events, related to hazards in the environment such as accidental falls or unsafe behaviour [27]. Patients referred for bone densitometry accept considerably higher fracture risk than doctors to justify drug treatment [28] and have difficulties understanding the concept of 10 year risk [27,29]. On the other hand, post-fracture osteoporosis medication use was higher in women than in men, in patients with previously diagnosed osteoporosis and in those who had a BMD assessment before the fracture [30].

Patients, the lay press, the medical literature and doctors, especially those treating tooth problems, have - sometimes excessive - concerns about side effects such as atypical femoral fractures (AFFs) and osteonecrosis of the jaw [31-33]. Other reasons for the evaluation and treatment gap are older age, residing in long-term care and lack of education about benefits and risks of treatment in patients, the lay press and even GPs $[8,34,35]$. In addition, there may be factors that attribute to the evaluation and treatment gap related to doctors and to local or national health organisations. Examples are the lack of a local bone leader and fracture nurse, lack of communication between specialists and between specialists and GPs, and insufficient organisational and financial support from local or national health organisations [10-13,15,18,36-39].

\section{Case finding: how to organise transfer from fracture treatment to secondary fracture prevention?}

Implementation of an FLS requires arranging systematic identification of all patients who enter the ED because of a fracture. Of the identified patients, those with following criteria need to be selected: $>50$ years old, excluding finger, toe, skull and pathologic and major traffic accident fractures. These selected patients then need to be informed about their potential subsequent imminent and long-term fracture risk and invited to attend the FLS for counselling, evaluation and treatment according to personalised precision medicine.

Many attempts have been undertaken to organise the transfer of patients with a recent fracture after acute fracture care towards secondary fracture prevention $[13,18]$.

Examples are education of patients with a recent fracture and alerting the GP by a discharge letter. However, such approach is less effective than an FLS [13].

\section{Which patients should be selected for evaluation at the FLS?}

Apart from orthopaedic descriptions of fractures (comminute, transverse, oblique etc.), there are many definitions in the literature for characterising the complex nature of a fracture (Fig. 2) [40-42]. 


\title{
'low-trauma osteoporotic', 'severe low-trauma' or 'major osteoporotic' fractures and 'clinical diagnosed osteoporosis'
}

\author{
'fall-related', 'atraumatic', 'non-traumatic', 'minimal- \\ trauma', 'low-trauma', 'low-energy trauma', \\ 'osteoporotic', 'osteoporosis-related', 'fragility', 'minor', \\ 'major', 'severe' \\ 'clinical', 'sub-clinical', 'radiographic', 'new vertebral', \\ 'worsening vertebral', 'vertebral deformity', \\ 'imminent fracture' \\ vertebral, non-vertebral, hip, non-vertebral non-hip, total \\ fractures, any clinical, around joints (shoulder, wrist) \\ comminute, transverse, oblique etc.
}

Fig. 2. Clouded Babylonian confusion about fracture denominations (after Brueghel).

These descriptions refer to different diagnostic skeletal and extra-skeletal characteristics associated with a fracture.

These variable fracture descriptions sometimes result in Babylonian confusion between clinicians regarding which patient with the above-described definitions to evaluate and treat in the context of the FLS. There is general consensus to invite following patients at the FLS:

- Women and men, 50 years or older, with a recent fracture

- All fracture locations (except fingers, toes, face and skull), and more specifically:

- Low trauma fractures, defined as fractures sustained due to fall(s) from standing height or lesser height and by extension of other low traumas (see above)

- Patients who sustain a moderate-to high-trauma fracture are also at increased risk of having subsequent fracture and could warrant inclusion (except after a major traffic accident) $[3,15,43]$.

\section{Which patients attend the FLS?}

Although VFs are the most common incident fractures after the age of 50 years in women and men [1], most patients who are visiting the Emergency Department present with an NVF [15]. Most VFs are not recognised because they occur sub-clinically, without typical clinical signs and symptoms of an acute fracture $[44,45]$, and because imaging of the spine is not performed in many patients with acute back pain [46]. In addition, VFs may not even be diagnosed when spine images are available [47], and, when diagnosed, they are often not treated or treated ambulatory [48].

In a recent overview, it was reported that FLSs varied in terms of patient identification, selection and FLS attendance [49]. Patient identification and selection differed markedly among FLSs, in terms of proportions of inpatients and outpatients, age, inclusion of women and/or men and fracture selection (any fracture or only patients with a NVF). Exclusion criteria for FLS invitation also differed, such as high-energy trauma fractures, pathological fractures and cognitive impairment. In addition, $20-89 \%$ of 
the patients selected for evaluation at the FLS actually attended the FLS. As a result, literature regarding FLSs contains a high variability in FLS patient characteristics, such as mean age (64-80 years), proportion of men (13-30\%) and fracture locations (2-51\% hip, <1-41\% vertebral and $49-95 \%$ non-hip, NVFs) [49].

In a national patient-level audit of the quality of FLSs in the UK, 18,356 patients were enrolled from 38 FLSs. It was concluded that national coverage of secondary fracture prevention using FLSs is still low with variability in quality between existing FLSs [50]. Although completeness of submitted data varied, there was also marked variability in the proportion of patients meeting recognised standards of care in the identification of fragility fracture patient, timely initial contact and subsequent risk assessment, and treatment initiation and monitoring [50].

In the Netherlands, where most of the hospitals run an FLS, in a study of 24,468 patients, those attending the FLS were evaluated, treated and followed in high compliancy with the local guidelines and with IOF standards [51]. However, the major shortcoming in FLS care was that patients invited to attend the FLSs showed a low attendance rate of approximately 50\%. The Kaiser Permanente Healthy Bones Program is yet another programme developed for fracture prevention [52]. Data gathered by the Capture the Fracture initiative of the IOF are available. It shows that currently $>300$ FLSs received a gold status worldwide [53].

\section{Fracture risk evaluation}

The aim of fracture risk evaluation after a recent fracture is, first, to identify the presence and extent of risk factors of having subsequent fracture risk and, second, initiate appropriate treatment according to the patient's risk.

Meanwhile, many risk factors for imminent subsequent fracture risk have been identified [6] (Table 1).

Clinical risk factors are included in fracture risk assessment tools such as FRAX [54], Garvan [55] and QFracture [56]. FRAX is developed at the University of Sheffield but is until now not endorsed by the WHO [54]. Although FRAX has been internationally validated at the population level, it underestimates the imminent subsequent fracture risk in 65 + patients with a recent fracture [57]. In a recent analysis of the Iceland population by the developers of FRAX, it was reported that in many cases after a recent fracture, the 10 year fracture probability for MOFs as calculated with FRAX underestimated the real imminent fracture risk by more than two-fold. Hazard ratio's ranged between 2.6 and 9.1, depending on the site of fracture, age and sex [58]. The FRAX-BMI scores were below the Canadian threshold for

\section{Table 1}

Risk factors for imminent subsequent fracture risk (adapted from Roux et al.) [6].

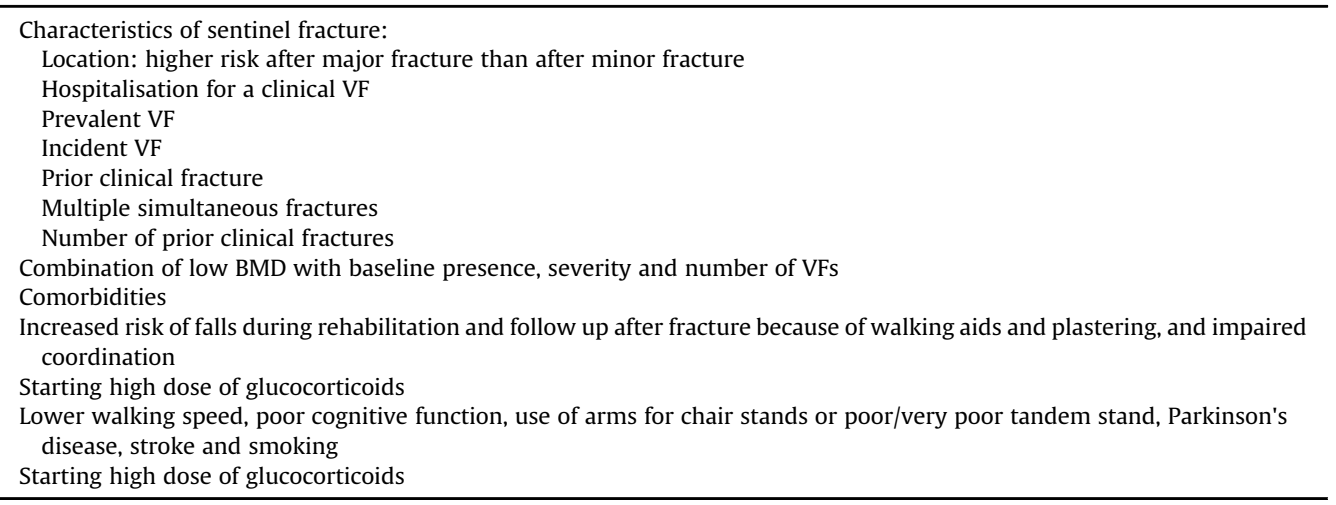


treatment in more than half of the patients at the time of a fragility fracture and in close to a third of patients with recurrent fragility fracture. One reason could be that FRAX does not specifically include the risk of falls [57,59]. The predictive potential of Garvan and QFracture algorithms, which include fall risks, has not been documented after a recent fracture.

These clinical risk factors occur at the background of other risks, such as low body mass index (BMI), lifestyle (smoking and alcohol) and family history of fractures [60-65].

Subsequent fracture risk is associated with low BMD at the hip, independent of age [66]. Measuring BMD after a recent fracture, therefore, contributes to fracture risk evaluation and specifies that the fracture in the patient is indeed 'osteoporotic'. In frail elderly with a hip fracture, DXA assessment will often be difficult to perform because of low health status, frailty, low mobility and referral to other locations such as a revalidation unit or rest home.

Half of the recurrent fractures occurred in patients with osteopenia, and subsequent fracture risk for low trauma fractures was highest in those who had a prevalent VF [2]. Sub-clinical VFs are frequently present in patients with a recent NVF [67,68]. Systematic guideline implementation resulted in a significant increase in imaging of the spine by DXA and diagnosis of VFs in patients visiting the FLS with an NVF in both genders, at any age, non-VF location and BMD [68]. Therefore, in many patients with a presumably first NVF, this fracture is, in fact, already a second fracture. In addition, evaluating the presence, number and severity of a VF by X-Ray or DXA contributes to identify patients at high risk of subsequent fractures, independent of BMD [69-71].

A history of fall during the last year is associated with a subsequent fracture, independent of a recent severe low-trauma fracture [72]. Many fall risk factors are related to an imminent fracture risk [73]. Therefore, fall risk evaluation by verifying the history of recent falls and medications and comorbidities that increase fracture risk contributes to fracture risk evaluation [72-74].

In the above cited overview of FLSs, there is a still high variability in the percentage of patients with osteoporosis (12-54\%), prevalent VFs (20-57\%) and fall-related risk factors (60-84\%) [49].

\section{Secondary osteoporosis and metabolic bone disorders}

Many conditions, diseases and medications have been shown to increase the risk of fractures [75]. Not surprisingly, many patients visiting the FLS report such diseases and medications in their medical history $[76,77]$. Approximately $23 \%$ reported a history of previously diagnosed diseases associated with increased fracture risk. However, metabolic bone disorders can be present subclinically and were diagnosed in $27 \%$ using a standard laboratory examination [77]. These subclinical newly diagnosed disorders, including low calcium intake and vitamin D deficiency, were found in both sexes, at all ages, after all fractures and at any level of BMD. Therefore, in addition to medical history, clinical examination and checking calcium intake and potential risks for vitamin D deficiency, a limited laboratory investigation is also recommended in all patients with a recent fracture. In the study of Bours et al. [77], these included serum calcium, albumin, phosphate, creatinine, TSH, alkaline phosphatase and ESR. Other tests can be performed when indicated, e.g. protein electrophoresis, testosterone in men less than 70 years old, $25(\mathrm{OH}) \mathrm{D}, \mathrm{PTH}$, tissue transglutaminase and anti-gliadin antibodies, 24-h urine collection (calcium, creatinine, sodium and phosphate), etc.

In the above-mentioned overview of 33 FLSs, 64\% performed laboratory tests [49]. There was a high variability of newly diagnosed contributors to secondary osteoporosis and other metabolic bone disorders (3-70\%) [49].

\section{Initiating and follow up of treatment}

Fractures should be managed in a multidisciplinary approach. Immediate treatment of the fracture led by a trauma or orthopaedic surgeon is needed, and in case of hospital admission, supportive care 
should be started and pre-existing comorbidities need attention in collaboration with a dedicated geriatrician [21].

As the FLS is considered the most effective organisation for evaluation and treatment initiation of secondary fracture prevention, an FLS visit is indicated for patients aged 50 years and over with a recent fracture. Treatment is preferably initiated by the supervising clinician at the FLS who is usually a rheumatologist, endocrinologist, internist or geriatrician, depending on the local situation, in collaborations with trauma or orthopaedic surgeons who are providing acute fracture care.

Organisation of FLS care for both inpatients and outpatients, including follow-up, is usually provided by a specialised FLS coordinator, usually an advanced practice provider $[18,78]$.

\section{Effect of FLS on evaluation, treatment initiation, subsequent fractures and mortality: is FLS cost-effective?}

Evaluation

Implementation of a structured FLS resulted in increased patient contacts and education and increased risk evaluation by DXA, by X-ray or DXA for imaging of the spine and by laboratory investigation $[10-12,68,79-83]$. In contrast, there was no change in exposure to drugs that are known to increase fracture risk [74].

\section{Therapy initiation}

Implementation of a structured FLS resulted in increased therapy initiation [13,14]. In hip fracture patients, FLS improved non-pharmacologic measures but not the use of osteoporosis medication [84].

Factors associated with post-fracture treatment included osteoporosis medication use before fragility fracture, higher daily calcium intake, diagnosis of osteoporosis, Asian or Pacific Islander race/ ethnicity (compared with White/Caucasian), higher income and hormone therapy use (past or present) $[12,85,86]$.

A reduced likelihood of osteoporosis medication use after a fracture included black race, higher Charlson Comorbidity Index scores, presence of dementia, kidney diseases, high BMI, current smoking and history of arthritis [86,87].

\section{Effect on subsequent fractures}

In a literature search of 22 reports of FLSs, only five FLS studies with heterogeneous study designs were available, which reported on subsequent fracture rate, and three of them reported a lower subsequent fracture rate related to FLS care when comparing fracture rates before and after the introduction of an FLS or when comparing hospitals with and without an FLS [88].

Using an interrupted time series analysis among hip fracture patients, publication of NICE guidance and availability of generic alendronic acid in the UK was associated with increased prescribing and a significant contemporary decline in subsequent major and hip fractures during three years [89]. In contrast, no reduction over two years in second hip fractures was found after introduction of FLS care [20], possibly because of low treatment adherence [20,89]. Brozek et al. found an increased subsequent fracture rate in bisphosphonate users after fracture, which they related not only to longer survival but also to the presence of more comorbidities in bisphosphonate users [90].

In a prospective cohort study during eight years of the Glasgow FLS in 5011 women and men, all patients received adequate calcium and vitamin $\mathrm{D}$, and those at high re-fracture risk were also recommended bisphosphonates $(\mathrm{n}=2534)$ [91]. After adjusting for baseline differences in age, sex and baseline fracture location, those recommended bisphosphonate treatment had a substantially lower risk for subsequent fragility fracture and mortality. 


\section{Effect on mortality}

Orthogeriatric care and FLS decreased mortality within 30 days and within one year in patients with a hip fracture [20,21,92]. In accordance with the reduced mortality with zoledronate after hip fracture [93], Brozek et al. [90] and Beaupre et al. [94] also reported a lower mortality in hip fracture patients treated with oral bisphosphonates. They also found an increased re-fracture rate, which they related not only to longer survival but also to more comorbidities in BP users [90]. In the above-mentioned long term of the Glasgow FLS, longer survival was also found in those treated for underlying osteoporosis [91].

\section{Cost effectiveness of FLS}

There is emerging literature about the cost effectiveness of FLS care [95], using health economic models for the evaluation of preventing fractures. Modelling techniques include simple decision trees, deterministic Markov processes and individual patient simulation models taking into account uncertainty in multiple parameters [95]. Economic evaluation can inform decision makers on the costeffectiveness of the various interventions and can be the basis for the allocation of scarce healthcare resources [96].

Using Markov models based on epidemiological data and results from RCTs on fracture incidence and prevention, models analysing the effect of treatment on secondary fracture prevention have been statistically shown to be cost-effective after a fragility fracture in preventing second osteoporotic fractures during a mean of six years follow-up [97] or in preventing second hip, wrist and humerus fractures during a mean of eight years follow-up [16].

During a mean follow up of 2.6 years, Leal et al. reported that introduction and/or expansion of Orthogeriatric and nurse-led FLS in patients with a recent hip fracture was more effective and costeffective than usual care, irrespective of age, sex and Charlson Comorbidity Index score [92]. However, when they incorporated the time to second hip fracture and death and the short- and long-term costs associated with patients with hip fracture, it was not cost-saving, presumably because longer survival could increase costs and re-fractures [92]. Considerable uncertainty remained concerning which of the models of care should be preferred [21,92]. RCTs have been conducted for the comparison of teriparatide with risedronate and romosozumab with alendronate $[98,99]$. In patients with VFs and a T-score $<-1.5$, teriparatide was superior to risedronate in preventing vertebral and clinical fractures. Pre-specified sub-group analyses indicated that this superior effect of teriparatide was consistent in a wide range of patients settings, including treatment naïve or previously treated patients, with or without a recent clinival VF or history of NVF and at any age or BMD [100]. In a similar high-risk population, including patients with a history of proximal femur fracture 3-24 months before randomisation, one year romosozumab followed by two years alendronate was superior to three years alendronate in the reduction of the risk of VFs, clinical fractures, NVFs and hip fracture [99]. Because of the higher cost of bone forming agents, direct cost/effectiveness comparisons with anti-resorptive therapy could contribute to select patients in whom bone forming agents can be started based on the level of subsequent fracture risk in daily practice.

\section{Summary}

The introduction and implementation of an FLS (and orthogeriatric care after hip fracture) have been shown to increase evaluation and treatment of patients at high risk of having subsequent fracture. There are emerging data that this approach decreases fracture and mortality risk, although longer survival could decrease the effect on fracture risk. Further research will be necessary to study the cost effectiveness of FLS care, based on real-world data and Markov models. 


\section{Practice points}

In view of the high imminent risk for subsequent fractures after a fracture, the fracture liaison service (FLS) (and orthogeriatric care after hip fracture) is considered the most appropriate organisational approach for secondary fracture prevention following a recent fracture.

Secondary fracture prevention after a recent fracture consists of four pillars:

1/ the logistics of an FLS for organising diagnostic evaluation and treatment decisions;

2/ orthogeriatric care after hip fracture;

3 / identification and invitation of patients with a recent fracture; and

4 / organising adequate follow up.

\section{Research agenda}

How to decrease the evaluation and treatment gap for secondary fracture prevention after a recent fracture?

How to improve adherence to therapy?

What is the cost/effectiveness of FLS and orthogeriatric care?

\section{Conflict of interest}

The authors have no conflict of interest in the context of this manuscript.

\section{Funding}

The authors received no funding for this manuscript.

\section{Acknowledgements}

None.

\section{References}

[1] Sambrook P, Cooper C. Osteoporosis. Lancet (London, England) 2006;367(9527):2010-8.

[2] Langsetmo L, Goltzman D, Kovacs CS, et al. Repeat low-trauma fractures occur frequently among men and women who have osteopenic BMD. J Bone Miner Res 2009;24(9):1515-22.

[3] Center JR. Fracture burden: what two and a half decades of dubbo osteoporosis epidemiology study data reveal about clinical outcomes of osteoporosis. Curr Osteoporos Rep 2017;15(2):88-95.

[4] Kanis JA, Johnell O, De Laet C, et al. A meta-analysis of previous fracture and subsequent fracture risk. Bone 2004;35(2): $375-82$.

[5] Klotzbuecher CM, Ross PD, Landsman PB, et al. Patients with prior fractures have an increased risk of future fractures: a summary of the literature and statistical synthesis. J Bone Miner Res 2010;15(4):721-39.

[6] Roux C, Briot K. Imminent fracture risk. Osteoporos Int 2017;28(6):1765-9.

[7] Giangregorio L, Papaioannou A, Cranney A, et al. Fragility fractures and the osteoporosis care gap: an international phenomenon. Semin Arthritis Rheum 2006;35(5):293-305.

[8] Kanis JA, Svedbom A, Harvey N, et al. The osteoporosis treatment gap. J Bone Miner Res 2014;29(9):1926-8.

[9] Greenspan SL, Wyman A, Hooven FH, et al. Predictors of treatment with osteoporosis medications after recent fragility fractures in a multinational cohort of postmenopausal women. J Am Geriatr Soc 2012;60(3):455-61. 
[10] Eisman JA, Bogoch ER, Dell R, et al. Making the first fracture the last fracture: ASBMR task force report on secondary fracture prevention. J Bone Miner Res 2012;27(10):2039-46.

[11] Akesson K, Marsh D, Mitchell PJ, et al. Capture the Fracture: a Best Practice Framework and global campaign to break the fragility fracture cycle. Osteoporos Int 2013;24(8):2135-52.

[12] Lems WF, Dreinhöfer KE, Bischoff-Ferrari H, et al. EULAR/EFORT recommendations for management of patients older than 50 years with a fragility fracture and prevention of subsequent fractures. Ann Rheum Dis May 2017:802-10.

[13] Ganda K, Puech M, Chen JS, et al. Models of care for the secondary prevention of osteoporotic fractures: a systematic review and meta-analysis. Osteoporos Int 2012;24(2):393-406.

[14] Majumdar SR, Beaupre LA, Harley CH, et al. Use of a case manager to improve osteoporosis treatment after hip fracture. Arch Intern Med 2007;167(19):2110.

[15] Geusens P, Eisman J, Singer A, van den Bergh J. In: Belizikian J, editor. Fracture liaison service, primer of the metabolic bone diseases and disorders of mineral metabolism. 9th ed. John Wiley \& Sons; 2019.

[16] McLellan AR, Wolowacz SE, Zimovetz EA, et al. Fracture liaison services for the evaluation and management of patients with osteoporotic fracture: a cost-effectiveness evaluation based on data collected over 8 years of service provision. Osteoporos Int 2011:22(7):2083-98.

[17] McLellan AR, Gallacher SJ, Fraser M, et al. The fracture liaison service: success of a program for the evaluation and management of patients with osteoporotic fracture. Osteoporos Int 2003;14(12):1028-34.

[18] Marsh D, Akesson K, Beaton DE, et al. Coordinator-based systems for secondary prevention in fragility fracture patients. Osteoporos Int 2011;22(7):2051-65.

[19] Jaglal SB, Donescu OS, Bansod V, et al. Impact of a centralized osteoporosis coordinator on post-fracture osteoporosis management: a cluster randomized trial. Osteoporos Int 2012;23(1):87-95.

[20] Hawley S, Javaid MK, Prieto-Alhambra D, et al. Clinical effectiveness of orthogeriatric and fracture liaison service models of care for hip fracture patients: population-based longitudinal study. Age Ageing 2016;45(2):236-42.

[21] Judge A, Javaid MK, Leal J, et al. Models of care for the delivery of secondary fracture prevention after hip fracture: a health service cost, clinical outcomes and cost-effectiveness study within a region of England. Health Serv Deliv Res 2016;4(28):1-170.

[22] Javaid MK, Kyer C, Mitchell PJ, et al. Effective secondary fracture prevention: implementation of a global benchmarking of clinical quality using the IOF Capture the Fracture(R) Best Practice Framework tool. Osteoporos Int 2015;26(11):2573-8.

[23] Curtis EM, Moon RJ, Harvey NC, et al. The impact of fragility fracture and approaches to osteoporosis risk assessment worldwide. Bone 2017 Nov;104:29-38.

[24] Kanis JA, Borgström F, Compston J, et al. SCOPE: a scorecard for osteoporosis in Europe. Arch osteoporos 2013;8(1-2): 144.

[25] Siris ES, Gehlbach S, Adachi JD, et al. Failure to perceive increased risk of fracture in women 55 years and older: the Global Longitudinal Study of Osteoporosis in Women (GLOW). Osteoporos Int 2011;22(1):27-35.

[26] Gregson CL, Dennison EM, Compston JE, et al. Disease-specific perception of fracture risk and incident fracture rates: GLOW cohort study. Osteoporos Int 2014;25(1):85-95.

[27] Alami S, Hervouet L, Poiraudeau S, et al. Barriers to effective postmenopausal osteoporosis treatment: a qualitative study of patients' and practitioners' views. PLoS One 2016;11(6):e0158365.

[28] Douglas F, Petrie KJ, Cundy T, et al. Differing perceptions of intervention thresholds for fracture risk: a survey of patients and doctors. Osteoporos Int 2012;23(8):2135-40.

[29] Sale JE, Gignac MA, Hawker G, et al. Patients do not have a consistent understanding of high risk for future fracture: a qualitative study of patients from a post-fracture secondary prevention program. Osteoporos Int 2016;27(1):65-73.

[30] Yusuf AA, Matlon TJ, Grauer A, et al. Utilization of osteoporosis medication after a fragility fracture among elderly Medicare beneficiaries. Arch Osteoporos 2016;11(1):31.

[31] Rizzoli R, Biver E, Bonjour JP, et al. Benefits and safety of dietary protein for bone health-an expert consensus paper endorsed by the european society for clinical and economical aspects of osteopororosis, osteoarthritis, and musculoskeletal diseases and by the international osteoporosis foundation. Osteoporos Int 2018 Sep;29(9):1933-48.

[32] Khosla S, Cauley JA, Compston J, et al. Addressing the crisis in the treatment of osteoporosis: a path forward. J Bone Miner Res 2017 Mar:32(3):424-30.

[33] K G. Citing risks, U.S. will halt study of drugs for hormones. N Y Times 2002 July 9. 2002.

[34] Solomon DH, Johnston SS, Boytsov NN, et al. Osteoporosis medication use after hip fracture in U.S. Patients between 2002 and 2011. J Bone Miner Res 2014;29(9):1929-37.

[35] Yood RA, Mazor KM, Andrade SE, et al. Patient decision to initiate therapy for osteoporosis: the influence of knowledge and beliefs. J Gen Intern Med 2008;23(11):1815-21.

[36] Abrahamsen C, Norgaard B, Draborg E, et al. Reflections on two years after establishing an orthogeriatric unit: a focus group study of healthcare professionals' expectations and experiences. BMC Health Serv Res 2017;17(1):602.

[37] Vaculik J, Stepan JJ, Dungl P, et al. Secondary fracture prevention in hip fracture patients requires cooperation from general practitioners. Arch Osteoporos 2017;12(1):49.

[38] Drew S, Judge A, May C, et al. Implementation of secondary fracture prevention services after hip fracture: a qualitative study using extended Normalization Process Theory. Implement Sci 2015;10:57.

[39] Mendis AS, Ganda K, Seibel MJ. Barriers to secondary fracture prevention in primary care. Osteoporos Int 2017 Oct; 28(10):2913-9.

[40] Sebba A. Comparing non-vertebral fracture risk reduction with osteoporosis therapies: looking beneath the surface. Osteoporos Int 2008;20(5):675-86.

[41] Center JR. The definition and clinical significance of nonvertebral fractures. Curr Osteoporos Rep 2010;8(4):227-34.

[42] Siris ES, Adler R, Bilezikian J, et al. The clinical diagnosis of osteoporosis: a position statement from the national bone health alliance working group. Osteoporos Int 2014;25(5):1439-43.

[43] Warriner AH, Patkar NM, Yun H, et al. Minor, major, low-trauma, and high-trauma fractures: what are the subsequent fracture risks and how do they vary? Curr Osteoporos Rep 2011;9(3):122-8. 
[44] Fink HA, Milavetz DL, Palermo L, et al. What proportion of incident radiographic vertebral deformities is clinically diagnosed and vice versa? J Bone Miner Res 2005;20(7):1216-22.

[45] Fink HA, Litwack-Harrison S, Ensrud KE, et al. Association of incident, clinically undiagnosed radiographic vertebral fractures with follow-up back pain symptoms in older men: the osteoporotic fractures in men (MrOS) study. J Bone Miner Res 2017 Nov;32(11):2263-8.

[46] Ettinger B, Black DM, Nevitt MC, et al. Contribution of vertebral deformities to chronic back pain and disability. The Study of Osteoporotic Fractures Research Group. J Bone Miner Res 1992;7(4):449-56.

[47] Gehlbach SH, Bigelow C, Heimisdottir M, et al. Recognition of vertebral fracture in a clinical setting. Osteoporos Int 2000; 11(7):577-82.

[48] Ensrud KE, Schousboe JT. Clinical practice. Vertebral fractures. N Engl J Med 2011;364(17):1634-42.

[49] Vranken L, Wyers CE, van den Bergh JPW, et al. The phenotype of patients with a recent fracture: a literature survey of the fracture liaison service. Calcif Tissue Int 2017;11:669.

[50] Royal College of Physicians. FLS forward: identifying high-quality care in the NHS for secondary fracture prevention. London (UK): Royal College of Physicians; 2017.

[51] van den Berg P, Schweitzer DH, van Haard PMM, et al. Meeting international standards of secondary fracture prevention: a survey on Fracture Liaison Services in The Netherlands. Osteoporos Int 2015;26(9):2257-63.

[52] Dell R. Fracture prevention in kaiser Permanente southern California. Osteoporos Int 2011;22(S3):457-60.

[53] International Osteoporosis Foundation (IOF). Capture the Fracture. Map of best practice. International Osteoporosis Foundation (IOF); 2017. Available from: http://www.capturethefracture.org/map-of-best-practice.

[54] Kanis JA, Johnell O, Oden A, et al. FRAX and the assessment of fracture probability in men and women from the UK. Osteoporos Int 2008;19(4):385-97.

[55] Nguyen ND, Frost SA, Center JR, et al. Development of a nomogram for individualizing hip fracture risk in men and women. Osteoporos Int 2007;18(8):1109-17.

[56] Hippisley-Cox J, Coupland C. Predicting risk of osteoporotic fracture in men and women in England and Wales: prospective derivation and validation of QFractureScores. BMJ 2009;339:b4229.

[57] Roux S, Cabana F, Carrier N, et al. The world health organization fracture risk assessment tool (FRAX) underestimates incident and recurrent fractures in consecutive patients with fragility fractures. J Clin Endocrinol Metab 2014;99(7): $2400-8$.

[58] Kanis JA, Johansson H, Oden A, et al. Characteristics of recurrent fractures. Osteoporos Int 2018;29(8):1747-57.

[59] Kanis JA, Cooper C, Rizzoli R, et al. Review of the guideline of the American College of Physicians on the treatment of osteoporosis. Osteoporos Int 2018;29(7):1505-10.

[60] Curtis EM, Moon RJ, Harvey NC, et al. Reprint of: the impact of fragility fracture and approaches to osteoporosis risk assessment worldwide. Int J Orthop Trauma Nurs 2017;26:7-17.

[61] Ftouh S, Morga A, Swift C, et al. Management of hip fracture in adults: summary of NICE guidance. BMJ 2011;342:d3304.

[62] Zura R, Braid-Forbes MJ, Jeray K, et al. Bone fracture nonunion rate decreases with increasing age: a prospective inception cohort study. Bone 2017;95:26-32.

[63] Centre for Metabolic Bone Diseases UoS. FRAX ${ }^{\circledR}$ fracture risk assessment tool Sheffield UK2010. Available from: https:// www.sheffield.ac.uk/FRAX/index.aspx.

[64] Garvan Insititute of Medical Research. The garvan fracture risk calculator. Available from: https://www.garvan.org.au/ promotions/bone-fracture-risk/calculator/.

[65] ClinRisk. Q-fracture risc calculator. Secondary Q-fracture risk calculator. 2017. Available from: http://www.qfracture.org/.

[66] Center JR, Bliuc D, Nguyen TV, et al. Risk of subsequent fracture after low-trauma fracture in men and women. J Am Med Assoc 2007;297(4):387.

[67] Gallacher SJ, Gallagher AP, McQuillian C, et al. The prevalence of vertebral fracture amongst patients presenting with non-vertebral fractures. Osteoporos Int 2006;18(2):185-92.

[68] van der Velde RY, Bours SPG, Wyers CE, et al. Effect of implementation of guidelines on assessment and diagnosis of vertebral fractures in patients older than 50 years with a recent non-vertebral fracture. Osteoporos Int 2017;23(9):1458.

[69] Ross PD, Genant HK, Davis JW, et al. Predicting vertebral fracture incidence from prevalent fractures and bone density among non-black, osteoporotic women. Osteoporos Int 1993;3(3):120-6.

[70] Genant HK, Wu CY, van Kuijk C, et al. Vertebral fracture assessment using a semiquantitative technique. J Bone Miner Res 1993;8(9):1137-48.

[71] Siris ES, Genant HK, Laster AJ, et al. Enhanced prediction of fracture risk combining vertebral fracture status and BMD. Osteoporos Int 2007:18(6):761-70.

[72] Deloumeau A, Molto A, Roux C, et al. Determinants of short term fracture risk in patients with a recent history of lowtrauma non-vertebral fracture. Bone 2017 Dec;105:287-91.

[73] Bonafede M, Shi N, Barron R, et al. Predicting imminent risk for fracture in patients aged 50 or older with osteoporosis using US claims data. Arch osteoporos 2016;11(1):26.

[74] Munson JC, Bynum JPW, Bell J-E, et al. Patterns of prescription drug use before and after fragility fracture. JAMA Intern Med 2016;176(10):1531.

[75] Walker-Bone K. Recognizing and treating secondary osteoporosis. Nat Rev Rheumatol 2012;8(8):480-92.

[76] Bours SPG, van den Bergh JPW, van Geel TACM, et al. Secondary osteoporosis and metabolic bone disease in patients 50 years and older with osteoporosis or with a recent clinical fracture: a clinical perspective. Curr Opin Rheumatol 2014; 26(4):430-9.

[77] Bours SPG, van Geel TACM, Geusens PPMM, et al. Contributors to secondary osteoporosis and metabolic bone diseases in patients presenting with a clinical fracture. J Clin Endocrinol Metab 2011;96(5):1360-7.

[78] Miller AN, Lake AF, Emory CL. Establishing a fracture liaison service: an orthopaedic approach. J Bone Joint Surg Am Vol 2015;97(8):675-81.

[79] Inderjeeth C, Smeath A. Bones beyond 70-insights into osteoporosis management in the elderly. Aust Fam Physician 2010;39(10):767-72. 
[80] Ruggiero C, Zampi E, Rinonapoli G, et al. Fracture prevention service to bridge the osteoporosis care gap. Clin Interv Aging 2015;10:1035-42.

[81] Morrish DW, Beaupre LA, Bell NR, et al. Facilitated bone mineral density testing versus hospital-based case management to improve osteoporosis treatment for hip fracture patients: additional results from a randomized trial. Arthritis Rheum 2009;61(2):209-15.

[82] Yates CJ, Chauchard M-A, Liew D, et al. Bridging the osteoporosis treatment gap: performance and cost-effectiveness of a fracture liaison service. J Clin Densitom 2015;18(2):150-6.

[83] Majumdar SR, Johnson JA, Bellerose D, et al. Nurse case-manager vs multifaceted intervention to improve quality of osteoporosis care after wrist fracture: randomized controlled pilot study. Osteoporos Int 2011;22(1):223-30.

[84] Cosman F, Nicpon K, Nieves JW. Results of a fracture liaison service on hip fracture patients in an open healthcare system. Aging Clin Exp Res 2017;29(2):331-4.

[85] Keshishian A, Boytsov N, Burge R, et al. Examining the treatment gap and risk of subsequent fractures among females with a fragility fracture in the US Medicare population. Osteoporos Int 2017;28(8):2485-94.

[86] Sattari M, Cauley JA, Garvan C, et al. Osteoporosis in the women's health initiative: another treatment gap? Am J Med 2017;130(8):937-48.

[87] Keshishian A, Boytsov N, Burge R, et al. Examining the treatment gap and risk of subsequent fractures among females with a fragility fracture in the US Medicare population. Osteoporos Int 2017;17(12):1726.

[88] de Bruin IJA, Wyers CE, van den Bergh JPW, et al. Fracture liaison services: do they reduce fracture rates? Ther Adv Musculoskelet Dis 2017;9(7):157-64.

[89] Hawley S, Leal J, Delmestri A, et al. Anti-osteoporosis medication prescriptions and incidence of subsequent fracture among primary hip fracture patients in england and wales: an interrupted time-series analysis. J Bone Miner Res 2016; 31(11):2008-15.

[90] Brozek W, Reichardt B, Zwerina J, et al. Antiresorptive therapy and risk of mortality and refracture in osteoporosis-related hip fracture: a nationwide study. Osteoporos Int 2016;27(1):387-96.

[91] van Geel T, Bliuc D, Geusens PPM, et al. Reduced mortality and subsequent fracture risk associated with oral bisphosphonate recommendation in a fracture liaison service setting: a prospective cohort study. PLoS One 2018;13(6): e0198006.

[92] Leal J, Gray AM, Hawley S, et al. Cost-effectiveness of orthogeriatric and fracture liaison service models of care for hip fracture patients: a population-based study. J Bone Miner Res 2017 Feb;32(2):203-11.

[93] Lyles KW, Colón-Emeric CS, Magaziner JS, et al. Zoledronic acid and clinical fractures and mortality after hip fracture. N Engl J Med 2007;357(18):1799-809.

[94] Beaupre LA, Morrish DW, Hanley DA, et al. Oral bisphosphonates are associated with reduced mortality after hip fracture. Osteoporos Int 2011;22(3):983-91.

[95] Si L, Winzenberg TM, Palmer AJ. A systematic review of models used in cost-effectiveness analyses of preventing osteoporotic fractures. Osteoporos Int 2014;25(1):51-60.

[96] Hiligsmann M, Kanis JA, Compston J, et al. Health technology assessment in osteoporosis. Calcif Tissue Int 2013;93(1): $1-14$.

[97] Yong JHE, Masucci L, Hoch JS, et al. Cost-effectiveness of a fracture liaison service-a real-world evaluation after 6 years of service provision. Osteoporos Int 2015;27(1):231-40.

[98] Kendler DL, Marin F, Zerbini CAF, et al. Effects of teriparatide and risedronate on new fractures in post-menopausal women with severe osteoporosis (VERO): a multicentre, double-blind, double-dummy, randomised controlled trial. Lancet (London, England) 2018 Jan 20;391(10117):230-40.

[99] Saag KG, Petersen J, Brandi ML, et al. Romosozumab or alendronate for fracture prevention in women with osteoporosis. N Engl J Med 2017;377(15):1417-27.

[100] Geusens P, Marin F, Kendler DL, et al. Effects of teriparatide compared with risedronate on the risk of fractures in subgroups of postmenopausal women with severe osteoporosis: the VERO trial. J Bone Miner Res 2018;33(5):783-94. 